\title{
Chagas Disease in Dogs from Endemic Areas of Costa Rica
}

\author{
Victor M Montenegro/ ${ }^{+}$, Maurico Jiménez, JC Pinto Dias*, Rodrigo Zeledón \\ Escuela de Medicina Veterinaria, Universidad Nacional, Apartado Postal 86-3000, Heredia, Costa Rica *Centro de Pesquisas \\ René Rachou-Fiocruz, Belo Horizonte, MG, Brasil
}

Dogs with the presumptive diagnosis of Chagas disease are commonly sent to our School of Veterinary Medicine by independent veterinarians. This prompted us to evaluate the prevalence of canine trypanosomiasis in some villages of the Central Valley of Costa Rica.

A total of 54 dogs (21 males and 33 females) from five rural villages, with ages between 3 months and 10 years old, were bled and submitted to three serological tests: indirect immunofluorescence, indirect hemagglutination and ELISA. Among all animals, 15 (27.7\%) revealed antibodies (6 pure bred and 9 mongrels) and in 3 of them the parasite was also demonstrated by xenodiagnosis. All positive animals except 1, and 9 negative animals (control group) were examined by X-rays and electrocardiography, revealing different degrees of cardiomegaly and ECG alteration, consistent with Chagas disease pathology in one dog (SA-11) of the infected ones.

Examination of 50 inhabitants living in the houses where dogs and Triatoma dimidiata were found, yielded negative serological reactions. This was assumed to support the hypothesis that dogs are commonly infected by the oral route, a more effective means of infection compared with the vector transmission mechanism that occurs in humans.

Key words: Chagas disease - Trypanosoma cruzi - dogs - Costa Rica

Dogs have been considered important domestic reservoirs of Trypanosoma cruzi, the agent of Chagas disease, in most Latin American countries and in some areas of the United States (Zeledón 1974, Minter 1976, Mott et al. 1978, Tippit 1978, Gürtler et al. 1993, 1998, Barr 1991a, Meurs et al. 1998, Bradley et al. 2000). Furthermore, dogs are also common victims of the disease, developing chronic pathological alterations that resemble those detected in humans (Williams et al. 1977, Barr et al. 1989, 1991b, Andrade et al. 1997, Meurs et al. 1998). The main two phases of human infection (acute and chronic) can be reproduced in dogs (Andrade et al. 1997). Dogs have also been recommended as a good model for the study of pathological changes during the course of the disease (Laranja et al. 1948, 1949, Anselmi 1965, 1967, Lana et al. 1992, Machado et al. 2001) and also as natural sentinels in surveillance areas where a vector control campaign has been performed (Castañera et al. 1998).

During the last decade, numerous dogs have been referred to our School of Veterinary Medicine by independent veterinarians, with the provisional diagnosis of Chagas disease or with some cardiac failure of unknown origin. Some of them have been confirmed in our laboratory by serology and/or xenodiagnosis and some by necropsy at the pathology unit, mainly after sudden death (Berrocal et al. 1993).

The aim of this work was to evaluate the prevalence of canine trypanosomiasis, in villages of the Central Val-

${ }^{+}$Corresponding author. Fax: (506)237-9735. E-mail: vmonte@ns.medvet.una.ac.cr

Received 31 August 2001

Accepted 28 January 2002 ley of Costa Rica, including dog breeds from wealthy neighborhoods.

\section{MATERIALS AND METHODS}

Dog sample - A group of 54 dogs (21 males and 33 females) was examined and bled from the cephalic vein. The dogs came from five rural villages of the Central Valley: Chilamate de Poás (Province of Alajuela); San Rafael, San Isidro and Mercedes Norte (Province of Heredia); and Santa Ana (Province of San José). Twenty-five of these animals were of various standard breeds and 29 were mongrel dogs, with ages varying from 3 months to 10 years old. In all visited households, Triatoma dimidiata, the main vector of Chagas disease in the country, was found or, at least, adult insects had been noticed by the inhabitants when attracted to electric lights. In at least one case, the owners had constructed a kennel in the backyard and adult bugs were found there on different occasions.

Human sample - Blood samples were also taken from a group of 50 persons, who were the owners of the houses where the dogs lived, or neighbors of them. Their ages varied from 5 to 72 years, with a mean of $29.9 \pm 18.5$ years (S. D.). Of these persons 17 were men and 33 women.

Serology - For serological diagnosis in dogs, three different tests were performed: indirect immunoflorescence (IFAT) by using basically the method described by Alvarez et al. (1968) and an IgG anti-dog conjugate (SIGMA) (cut off: 1/32), the ELISA of Biozima kit (Polychaco), and the indirect hemagglutination (IHA) kit of Hemacruzi (Bio Merieux), following the instructions of each kit. Only those animals with a minimum of two positive tests were considered positive. In order to produce positive control sera for the tests, we infected two female mongrels (4 and 15 months old) previously demonstrated as negative by serology and xenodiagnosis. Both animals were given a 
suspension of feces of a naturally infected $T$. dimidiata, in $\mathrm{NaCl}$ physiological solution, containing 0.9 and $1.0 \mathrm{x}$ $10^{6}$ metacyclic forms respectively. The two dogs were inoculated by placing this suspension on their tongue and making them swallow. Infection was confirmed after 28 and 37 days respectively, by fresh blood examination, xenodiagnosis and serology.

For human sera the ELISA and the IHA test were used, employing the same cut-off of the reactions performed for the dogs.

Xenodiagnosis - These tests were performed in serologically positive dogs by using 20 fourth and fifth instar nymphs of laboratory reared Rhodnius prolixus originally from Honduras. The insects were examined individually at 30-60 days after feeding.

Radiologic and electrocardiographic examination. - Two thorax radiographies, one lateral and one dorsoventral, were performed in all serologically positive dogs, except in one, and in 10 negative control animals. Also, electrocardiograms (ECG), including the 12 leads, were conducted on these animals, by using a Hewlett-Packard 1500B equipment.

\section{RESULTS}

Of the $54 \mathrm{dogs}, 15$ (27.7\%) were shown to be infected with $T$. cruzi, 14 of these producing positive results in all three serological tests, and 1 in two tests. Two other animals were positive only in the ELISA test (Table I).

Through X-ray examination it was possible to detect different degrees of cardiomegaly or the enlargement of one or more of the chambers, in all of the 14 positive animals examined ( 1 dog died before the examination was performed): general cardiomegaly (1 dog), right cardiomegaly ( 3 dogs), enlargement of the right ventricle (3) or right atrium (4), and prominent bronchiolar pattern (3). Of the 9 negative dogs, 8 were normal in x-ray results and one had a right ventricular enlargement (Table II).

The ECGs also revealed different alterations. In the same 14 infected dogs we found right bundle branch block (1 dog), low voltage of the QRS complex (1), sinusal tachycardia (1), repolarization alterations (4 dogs), and $\mathrm{T}$ wave alterations (3). Sinusal arrhythmia was found in nine serologically positive dogs, and sinusal stops, in one. Two serologically positive dogs presented a normal ECG. One dog (SA-11) showed clinical symptoms, with dyspnea, loss of weight and ascitis, and almost 51 of serosanguinolent liquid was removed from the abdomen.

The negative control dogs presented sinusal arrhythmia (7), bradychardia (1), first degree alterations of repolarization (3), sinusal bradychardia (2), and atrium ventricular block (1). One of the negative dogs presented an idiopathic miocarditis. The ECG of this dog (MN-O7), showed low voltage of QRS complex and sinus arrhythmia, and there was evidence of general cardiomegaly in $\mathrm{X}$-ray examination. The animal died and the pathologist confirmed the presence of idiopathic degenerative miocarditis, with no signs of chagasic lesions in this animal.

All examined humans were revealed to be negative by ELISA and IHA test.

\section{DISCUSSION}

In Costa Rica, $T$. dimidiata is found inside and/or around houses and it is also well represented in wild ecotopes (Zeledón 1981). There is ample evidence for a permanent link between the wild cycle of T. cruzi, including mainly the common opossum (Didelphis marsupialis) as reservoir, and the domestic cycle involving the same vector, $T$. dimidiata. The insect can be brought passively

TABLE I

Infected dogs with Trypanosoma cruzi and main findings

\begin{tabular}{|c|c|c|c|c|c|c|c|c|c|c|c|}
\hline \multirow[t]{2}{*}{ No. } & \multirow[t]{2}{*}{ Dog } & \multirow[t]{2}{*}{ Sex } & \multirow{2}{*}{$\begin{array}{c}\text { Age } \\
\text { (years) }\end{array}$} & \multirow[t]{2}{*}{ Breed } & \multirow[t]{2}{*}{ Origin } & \multicolumn{3}{|c|}{ Serology } & \multirow[t]{2}{*}{ ECG } & \multirow[t]{2}{*}{$\mathrm{RX}$} & \multirow[t]{2}{*}{$\mathrm{XE}$} \\
\hline & & & & & & IFAT & ELISA & IHA & & & \\
\hline 1 & SR-01 & $\mathrm{F}$ & 7 & Pekinese & Sn. Rafael Heredia & + & + & + & $1-3-4$ & 12 & - \\
\hline 2 & SR-06 & M & 3 & Mongrel & Sn. Rafael Heredia & + & + & + & 1 & 13 & - \\
\hline 3 & SR-07 & M & 5 & Mongrel & Sn. Rafael Heredia & + & + & + & $1-3$ & 14 & - \\
\hline 4 & SR-08 & $\mathrm{F}$ & 2 & German Shepherd & Sn. Rafael Heredia & + & + & + & 1 & 12 & - \\
\hline 5 & SR-09 & $\mathrm{F}$ & 3 mo. & Mongrel & Sn. Rafael Heredia & + & + & + & $1-4$ & $\mathrm{BNL}$ & - \\
\hline 6 & CHP-O3 & M & 3 & Mongrel & Chilamate Poás & + & + & + & $1-11$ & 12 & - \\
\hline 7 & CHP-04 & $\mathrm{F}$ & 3 & Mongrel & Chilamate Poás & + & + & + & ND & ND & - \\
\hline 8 & MN-01 & $\mathrm{F}$ & 7 & Cocker & Mercedes N Heredia & + & + & + & 1 & 16 & + \\
\hline 9 & $\mathrm{MN}-02$ & $\mathrm{~F}$ & 7 & Mongrel & Mercedes N Heredia & + & + & + & $\mathrm{BNL}$ & 14 & ND \\
\hline 10 & SA-06 & $\mathrm{F}$ & 3 & Jack Russell & Santa Ana & + & + & + & $3-4$ & $12-15$ & - \\
\hline 11 & SA-07 & $\mathrm{F}$ & 4 & Corgy & Santa Ana & + & + & + & BNL & 13 & - \\
\hline 12 & SA-11 & $\mathrm{F}$ & 7 & Saint Bernard & Santa Ana & + & + & + & $7-8-9$ & 13 & + \\
\hline 13 & SA-14 & $\mathrm{F}$ & 3 & Mongrel & Santa Ana & + & + & + & 1 & 14 & - \\
\hline 14 & SA-15 & $\mathrm{F}$ & 2 & Mongrel & Santa Ana & + & + & + & $1-3$ & $15-16$ & - \\
\hline 15 & SA-17 & $\mathrm{F}$ & $3 \mathrm{mo.}$ & Mongrel & Santa Ana & + & + & + & 10 & $15-16$ & + \\
\hline
\end{tabular}

1: sinusal arrhythmia; 2: bradycardia; 3: first degree repolarization alteration; 4: T wave alteration; 5: sinusal bradycardia; 6: first degree atrium-ventricular block; 7: right bundle branch block; 8: low QRS complex voltage; 9: sinusal tachycardia; 10: left ventricular enlargement; 11: arrhythmia with sinusal stops; 12: right atrium enlargement; 13: right cardiomegaly; 14: right ventricular enlargement; 15: bronchial pattern; 16 : general cardiomegaly

BNL: between the normal limits; mo: months; ND: not done; the dog died before the test was performed; Xe: xenodiagnosis 
TABLE II

Dogs not infected with Trypanosoma cruzi and main findings

\begin{tabular}{|c|c|c|c|c|c|c|c|c|c|c|}
\hline \multirow[t]{2}{*}{ No. } & \multirow[t]{2}{*}{ Dog } & \multirow[t]{2}{*}{ Sex } & \multirow[t]{2}{*}{ Age } & \multirow{2}{*}{$\begin{array}{l}\text { Breed } \\
\text { (years) }\end{array}$} & \multirow[t]{2}{*}{ Origin } & \multicolumn{3}{|c|}{ Serology } & \multirow[t]{2}{*}{$\mathrm{ECG}^{a}$} & \multirow[t]{2}{*}{$\mathrm{RX}^{a}$} \\
\hline & & & & & & IFAT & ELISA & IHA & & \\
\hline 1 & CHP-01 & $\mathrm{F}$ & 1 & Mongrel & Poás & - & - & - & 1 & BNL \\
\hline 2 & CHP-11 & M & $8 \mathrm{mo.}$ & Mongrel & Poás & - & - & - & $\mathrm{BNL}$ & $\mathrm{BNL}$ \\
\hline 3 & SA-01 & $\mathrm{F}$ & 2 & Schnauzer & Sta. Ana & - & - & - & BNL & BNL \\
\hline 4 & SA-02 & $\mathrm{F}$ & 2 & Schnauzer & Sta. Ana & - & - & - & $\mathrm{BNL}$ & BNL \\
\hline 5 & SA-03 & M & 1 & Schnauzer & Sta. Ana & - & - & - & 1 & BNL \\
\hline 6 & SA-08 & M & 4 & Pomeranian & Sta. Ana & - & - & - & 1 & BNL \\
\hline 7 & SA-09 & M & 8 & Schnauzer & Sta. Ana & - & - & - & 1 & BNL \\
\hline 8 & SR-O2-1 & M & $5 \mathrm{mo.}$ & Mongrel & Sn. Rafael Heredia & - & - & - & $1-3$ & BNL \\
\hline 9 & MN-07 & $\mathrm{F}$ & 10 & $\begin{array}{l}\text { Australian } \\
\text { Blue hiller }\end{array}$ & Mercedes Norte Heredia & - & - & - & $1-8$ & 16 \\
\hline
\end{tabular}

$a:$ as in Table I

to households with firewood or adult bugs can fly directly, attracted by lights (Zeledón et al. 1973, 1975). By precipitin tests, it has also been demonstrated that the animal most frequently bitten by intradomiciliary and peridomiciliary bugs are dogs (Zeledón et al. 1973). It is also important to remember that $T$. dimidiata is a species with a strong tendency to become established under urban or periurban conditions (Zeledón 1981).

Rural houses and sometimes poor urban houses represent a good ecotope in which T. dimidiata can thrive. On the other hand, well constructed houses, in areas surrounded by coffee plantations or by brush, in villages located close to the main cities, can frequently be visited by adult insects attracted to lighting, without becoming infested. In both cases dogs have a good chance of coming in contact with these insects, particularly adults, which in the case of $T$. dimidiata are quite conspicuous, prompting dogs to seize them with their mouths (Zeledón et al. 2001).

It is normally assumed that dogs become infected in the same way as humans, i.e., by contamination with infected feces or urine from the insect vector, through abraded skin or conjunctiva. Despite frequent reports of dogs and other animals chewing the insect or at least grabing it with their mouths, as an instinctive act (Wood \& Wood 1964, Zeledón 1974), little attention has been given to this mechanism of infection. Experimentally, this route is extremely effective for laboratory, domestic or wild animals, indicating that some of them, under natural conditions, will become more easily infected and that this mechanism should be considered of great epidemiological importance (Zeledón et al. 1977).

This would explain the relatively high prevalence indices of $T$. cruzi infections in dogs in some areas, even though, when this occurs in the outdoor areas of high income households, as in some of our cases, the possibilities of human infections are remote. In these cases there are commonly one or more expensive dog breeds, which often remain all night in the surrounding gardens as watch dogs, and when they become ill the owners seek veterinary advice.

Our results confirm the more frequent infection of dogs than of humans, probably due to the more effective mechanism of infection in dogs via the mouth and to the rather low vectorial capacity of $T$. dimidiata by the conventional method of transmission (Zeledón 1974, 1981). The mouth is an effective means of infection in wild and laboratory animals but to our knowledge there are no studies on the experimental infection of dogs with insect feces, using the mouth as a route of infection.

The significantly higher prevalence rates found in dogs in other countries, as compared with human rates (Wisnivesky-Colli et al. 1985), might be explained by this oral mechanism of infection. This may also be the case of dog infections in some counties of Texas, United States, where infections probably occur through contact with wild bugs such as T. lecticularia, and where human infection is rare or does not exist (Wood \& Wood 1964, Williams et al. 1977). Also, in the Argentinean "chaco", young sentinel dogs may become easily infected, possibly by picking up peridomestic T. guasayana with their mouths, when this insect replaces the common vector $T$. infestans after insecticide control campaigns (Castañera et al. 1998). As the latter authors state "dogs appear to be effective sentinels of transmission mediated by sylvatic triatomines". We believe that what is being used as a sentinel is an animal that offers a more effective mechanism of acquiring Chagas disease, before transmission becomes established among humans.

It seems evident that dogs infected with $T$. cruzi could develop, in the chronic phase, mainly a right sided cardiac dysfunction as stressed by Tippit (1978). Some of the most common ECG alterations described in experimentally or in naturally infected dogs are: extrasystolic ventricular tachycardia, ventricular extrasystols, $\mathrm{A}-\mathrm{V}$ and right bundle branch blocks, $\mathrm{T}$ wave changes, low voltage of the QRS complex and prolonged PR interval (Pellegrino et al. 1947, Laranja et al. 1949, Tippit 1978, Lana et al. 1992, Meurs et al. 1998). The alterations we found, both by Xrays and ECGs in some of our positive dogs, coincide with what has been reported in the literature, but they were not as common as in other reports and only one dog showed the more typical alterations, probably due to a more prolonged period of infection. In one experimental study other authors described some of the typical signs in the ECG, but the alterations tended to become normal 
after three months of infection even though they might reappear during the chronic phase of the disease (Lana et al. 1992). In our case we did not know the period of infection and probably the majority of the seropositive dogs were in an early chronic phase of the illness as inferred from the ECG alterations.

We conclude that canine trypanosomiasis is a rather common disease in different areas of Costa Rica, frequently caused by infected adults of $T$. dimidiata flying to lights of modern houses, where they are found the next morning by the dogs' owners. Infection occurs outdoors when the dog catches, or chews the insects. The same phenomenon may occur in poor rural households where the insect finds conditions to breed and the victims are mongrel dogs with little or no economic implications, but the epidemiological consequences are obviously important. In both situations the disease can reach different pathological levels, with an acute phase that can be fatal in young animals, and a chronic phase with a cardiopathy pattern that can sometimes lead to sudden death.

\section{ACKNOWLEDGMENTS}

To Dr Jorge Yanovsky from Polychaco S.A.I.C., Buenos Aires, Argentina, for facilitating the immunoenzimatic kits (Biozima) and Dr Paul Hanson from the School of Biology, University of Costa Rica for revision of the manuscript.

\section{REFERENCES}

Alvarez M, Cerisola J, Rohwedder R 1968. Test de inmunofluorescencia para diagnóstico de la enfermedad de Chagas. Bol Chile Parasitol 23: 4-9.

Andrade ZA, Andrade SG, Sadigursky M, Wenthold RJ, Hilbert Jr SL, Ferrans VJ 1997. The indeterminate phase of Chagas' disease: ultraestructural characterization of cardiac changes in the canine model. Am J Trop Med Hyg 57: 328-336.

Anselmi A, Gurdiel O, Suárez J, Anselmi G 1967. Disturbances in the A-V conduction system in Chagas' myocarditis in the dog. Circ Res 20: 56-63.

Anselmi A, Pifano F, Suarez A, Domíngez A, Anselmi G 1965. Experimental Schizotrypanum cruzi myocarditis. Am Heart J 70: 638-656.

Barr S, Dennis V, Klei T 1991a. Serologic and blood culture survey of Trypanosoma cruzi infection in four canine populations of southern Louisiana. Am J Vet Res 52: 570-573.

Barr SC, Schmidt S, Brown C, Klei T 1991b. Pathologic features of dogs inoculated with North American Trypanosoma cruzi isolates. Am J Vet Res 52: 2033-2039.

Barr SC, Simpsom M, Schmidt SP, Bunge MM, Authement JM, Lozano F 1989. Chronic dilatative myocarditis caused by Trypanosoma cruzi in two dogs. JAVMA 195: 12371240.

Berrocal A, Morales JA, Cordero V, Villalobos C 1993. Miocarditis aguda chagásica en caninos de Costa Rica. Cien Vet (Costa Rica) 15: 51-59.

Bradley KK, Bergman DK, Woods JP, Crutcher JM, Kirchhoff LV 2000. Prevalence of American trypanosomiasis (Chagas disease) among dogs in Oklahoma. JAVMA 217: 1853-1857.

Castañera MB, Lauricella MA, Chuit R, Gürtler RE 1998. Evaluation of dogs as sentinels of the transmission of Trypanosoma cruzi in a rural area of north-western Argentina. Ann Trop Med Parasitol 92: 671-683.

Gürtler RE, Cécere MC, Petersen MR, Rubel ND, Schwigmann NJ 1993. Chagas' disease in north-west Argentina: associa- tion between Trypanosoma cruzi parasitemia in dogs and cats and infections rates in domestic Triatoma infestans. Trans R Soc Trop Med Hyg 87: 12-15.

Gürtler RE, Cohen JE, Cecere MC, Lauricella MA, Chuit R, Segura EL 1998. Influence of humans and domestic animals on the household prevalence of Triatoma infestans populations in Norwest Argentina. Am J Trop Med Hyg 58: 748758.

Lana M, Chiari E, Tafuri W L 1992. Experimental Chagas' disease in dogs. Mem Inst Oswaldo Cruz 87: 59-71.

Laranja F, Dias E, Nobrega G 1948. Clínica e terapêutica da doença de Chagas. Mem Inst Oswaldo Cruz 46: 473-529.

Laranja F, Pellegrino J, Dias E 1949. Experimental Chagas heart disease (Abstract). Am Heart J 37: 646.

Machado EMM, Camilo Jr DJ, Pinheiro SW, Lopes ER, Fernandes AJ, Dias JCP, Addad SJ 2001. Morphometry of submucous and menteric esophagic plexus of dogs experimentally infected with Trypanosoma cruzi. Mem Inst Oswaldo Cruz 96: 545-548.

Meurs KM, Anthony MA, Slater M, Miller MW 1998. Chronic Trypanosoma cruzi infection in dogs: 11 cases (1987-1996). JAVMA 213: 497-500.

Minter DM 1976. Effects of transmission to man of the presence of domestic animals in infested households. PAHO Sci Pub 318: 330-337.

Mott KE, Mota EA, Sherlock I, Hoff R, Muñiz TM, Oliveira TS, Draper C 1978. Trypanosoma cruzi infection in dogs and household seroreactivity to Trypanosoma cruzi in a rural comunity in northest Brazil. Am J Trop Med Hyg 27: 1123-1127.

Pellegrino J 1947. O electrocardiograma na doença de Chagas experimental no cão. Brasil Med 61: 3-10.

Tippit T 1978. Canine trypanosomiasis (Chagas' disease). South Vet 31: 97-104.

Williams GD, Adams G, Yaeger RG, Mc Grath KK, Read WK, Bidelback WR 1977. Naturally ocurring trypanosomiasis (Chagas' disease) in dogs. JAVMA 15: 171-177.

Wisnivesky-Collie C, Gurtler RE, Solarz ND, Lauricella MA, Segura MA 1985. Epidemiological role of humans, dogs and cats in the transmision of Trypanosoma cruzi in a Central area of Argentina. Rev Inst Med Trop São Paulo 27: 346352.

Wood S, Wood F 1964. New locations for Chagas' trypanosome in California. Bull South Calif Ac Sci 63: 104-111.

Zeledón R 1974. Epidemiology, modes of transmission and reservoir hosts of Chagas' disease. In Trypanosomiasis and Leishmaniasis with Special Reference to Chagas Disease, Ciba Foundation Symposium 20 (new series), p. 51-77.

Zeledón R 1981. El Triatoma dimidiata (Latreille, 1811) y su Relación con la Enfermedad de Chagas, UNED, San José, Costa Rica, 146 pp.

Zeledón R, Montenegro VM, Zeledón O 2001. Evidence of colonization of man-made ecotopes by Triatoma dimidiata (Latreille, 1811) in Costa Rica. Mem Inst Oswaldo Cruz 96: 659-660.

Zeledón R, Solano G, Burstin L, Swartzwelder JC 1975. Epidemiological pattern of Chagas' disease in an endemic area of Costa Rica. Am J Trop Med Hyg 24: 214-225.

Zeledón R, Solano G, Zúñiga A, Swartzwelder JC 1973. Biology and ethology of Triatoma dimidiata (Latreillie, 1811). III. Habitat and blood sources. J Med Entomol 10:363-370.

Zeledón R, Trejos de M, Chinchilla M 1977. Experimental infection of mice with blood, culture and insect forms of Trypanosoma cruzi by diferents routes. Protozoology 3: 95-101. 